\title{
Application Investigation on the Virtual Experiment Platform for Civil Engineering Specialty
}

\author{
Chunzhi Zhang*, Min Chen, Qianjun Mao \\ Wuhan University of Science \& Technology, Wuhan, Hubei, P.R. China \\ "Corresponding author. Email: zhangchunzhi@wust.edu.cn
}

\begin{abstract}
In order to strengthen the cultivation of students' practical procedures and engineering abilities, Colleges and Universities have established virtual simulation experiment platforms. The various virtual simulation experiment platforms provide the convenient way for practice. In this paper, the application effect of virtual simulation experiment platform was investigated. There are 119 items of virtual simulation experiment platforms for civil engineering speciality on the national virtual simulation experiment sharing platform web, and the visit quantities of many platforms are less 10,000.And there are 95 items which the evaluation score is over 4.8. According to the online-questionnaire results, $81 \%$ of application is for graduation practice, $69 \%$ of the students think the virtual simulation experiment procedure is easy to operate, more than $90 \%$ of the students think that the virtual simulation platforms can not replace the traditional on-site practice. The investigation results indicate that the practical teaching of civil engineering specialty need online and offline ways to carry out.
\end{abstract}

Keywords: Virtual reality technology, Civil engineering specialty, Practical teaching, Practical ability.

\section{INTRODUCTION}

Virtual reality technology can provide users with sensory simulation of visual, auditory and tactile, and users can observe the three-dimensional virtual world on time and unrestricted ways [1]. The application of virtual reality technology in education is the most revolutionary. Some developed countries have set up relevant research projects, such as the virtual world working group established by Australia and New Zealand in 2009 and the Second Life project of linden laboratory in the United States [2]. Among them, the Second Life project directly proposes to explore the possibility of individual education and growth in the virtual reality world. At present, $80 \%$ of universities in the UK are applying or planning to use the Second Life platform, and more than 150 universities in the United States have built the virtual scenes for teaching and research in the Second Life.

Now in China, virtual reality technology is widely used in the fields of education, medical, road and bridge construction, industrial manufacturing and so on, and also provides practical solutions for the development of the industry. Especially in the field of education, virtual reality technology can not only flexibly and vividly show the teaching content, but also customize a similar real practice environment for students through a simulation scene, which provides a new way to develop the practice teaching in Colleges and Universities. Practice teaching is an important teaching process in Colleges and Universities to improve the professional knowledge application ability and cultivate analysis and innovation ability for students. But now there are more and more problems to make the practice teaching difficult to carry out, such as no standardized and perfect internship measures in enterprises, the students' safety problems at the construction site during internship, inflexibility for practice arrangement, nonstandard evaluation system and so on, then it is hard to attain ideal effect for students in practice teaching. How to heighten students' practical ability and cultivate highquality talents to meet the requirements of society is the most priority in the changes of students' practical teaching in Colleges and Universities [3]. 


\section{THE NECESSITY TO BUILD VIRTUAL PLATFORM FOR STUDENTS OF CIVIL ENGINEERING SPECIALTY}

\subsection{Requirements of Practical Teaching for Civil Engineering Professional Certification Evaluation}

The evaluation standard of undergraduate education for engineering majors puts forward specific requirements for professional teaching. In addition to strengthen the basic theory of the major, it also emphasizes the importance of practice and engineering concept. The evaluation (certification) standard requires the engineering graduates to achieve six abilities: practice and application ability, ability to solve engineering technical problems, operation and maintenance ability, expression ability, computer application ability and integrated innovation ability. The certification standard emphasizes the teaching of students' practice, and details provisions from the experimental teaching (which includes cognitive, confirmatory, comprehensive and designed experiments) to the topic selection and content of curriculum design and graduation design, from the engineering background of the teaching staff to the experimental conditions and practice bases [4]. It indicates that the practical teaching of engineering specialty is very important.

\subsection{Problems in Practical Teaching Process of Civil Engineering Specialty}

With the development of economy, there are too many large-scale construction built at cities.It should not be difficult for students of civil engineering specialty to participate the actual project construction. However, because of dangerous at the construction sites, the builders and constructors generally do not allow students to participate in the construction of the project. Some construction sites simply refuse students to practice, even if they are reluctant to accept students internship, the students also cannot do something at the site, just be a bystander, or learning the drawings in the office of the construction site during internship period, which leads to the internship becoming a mere formality. Secondly, the specialty involves a wide range and complex construction engineering structure, long construction period, and is limited by the site and internship time. Most of the students have not been exposed to the practice of construction engineering, and lack of understanding of construction engineering When students visit the actual project, they can only see fragments or fragmented scenes. Some projects or equipment are highly hidden, and students can only see parts of the system on site. The integrity of the system is poor, and they know less about its installation and construction. These limitations make it difficult for students to heighten their practical ability and the ability to solve engineering problems.

\subsection{Ways for Solving Practical Teaching Problems of Civil Engineering Specialty}

In view of the above problems, virtual reality technology is a good way. Applying virtual reality technology to establish a virtual practice base, its "equipment" and "parts" are mostly virtual, and new equipment or systems can be generated at any time according to the teaching demand. The teaching content can be constantly updated, so that the practical training can keep up with the development of technology in time. At the same time, the immersion and interaction of virtual reality enable students to play roles in the virtual learning environments and devote themselves to the learning environments, which is very conducive to the improvement of students' practical ability. The virtual laboratory based on virtual reality technology can solve the limitation of hardware, such as equipment, site and funds. Students can do all kinds of experiments on the Internet at any time according to their own time, and get the same experience as real experiments. Under the premise of ensuring the teaching effect, the cost is greatly saved. Secondly, it can avoid all kinds of dangers brought by real experiments or operations, and use virtual reality technology to carry out virtual experiments. Students can safely do all kinds of dangerous experiments in the virtual experimental environment. For example, virtual chemical experiments can avoid the dangers caused by combustion and explosion caused by chemical reactions. Using virtual technology can effectively solve the contradiction between the above practice place, experimental conditions and experimental effect [6].

\subsection{Construction of Virtual Simulation Experiment Platform on Civil Engineering}

According to the national virtual simulation experiment sharing platform, 119 virtual simulation experiment projects have been built from 2017 to 2020, of which 13 projects are national recognized projects and 106 projects are the others. Among the 13 identified projects, 11 of them are civil engineering experimental projects, 1 project is about the building environment and energy application engineering professional project, and 1 is about the building electrical and intelligent experimental project. The number of visits and scores of the 119 projects identified virtual simulation projects are shown in Table 1 below. 
Table 1. Visits and rating data of projects

\begin{tabular}{|l|l|l|l|l|l|l|l|l|l|c|c|}
\hline Items & \multicolumn{7}{|c|}{ Statistical data } & Sum \\
\hline $\begin{array}{l}\text { evaluation } \\
\text { score }\end{array}$ & 5 & 4.9 & 4.8 & 4.7 & 4.6 & 4.5 & 4.4 & 4.2 & 3.7 & 3.5 & $/$ \\
\hline numbers & 45 & 30 & 20 & 7 & 7 & 3 & 3 & 1 & 2 & 1 & 119 \\
\hline
\end{tabular}

Among them, the visits and evaluation scores of 119 projects are shown in Figure 1

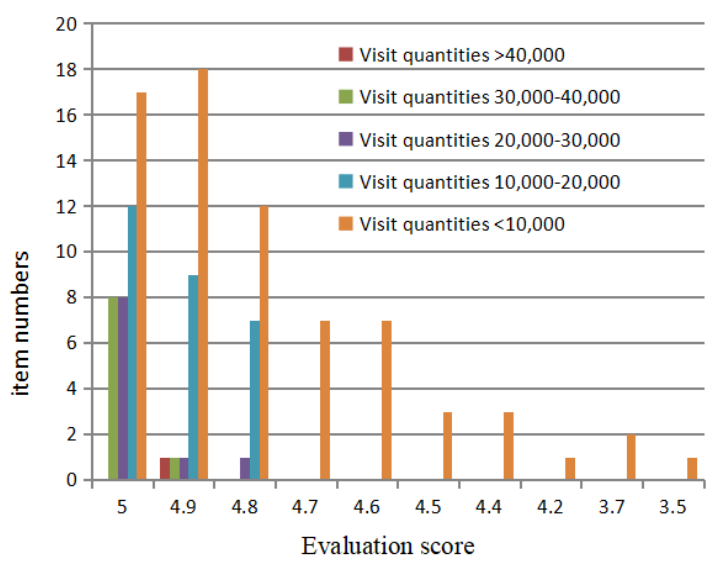

Figure 1 Relationship on project of visits and evaluation

As Figure 1 shown, there are 95 projects with a score of 4.8-5.0, and the visits is less than 10,000. It indicates that the virtual simulation project experimental platform has not been widely used, and its usage is not founded.

\section{APPLICATION EFFECT OF VIRTUAL PRACTICE PLATFORMS FOR STUDENTS OF CIVIL ENGINEERING SPECIATLY}

\subsection{Questionnaire for the Simulation Platforms of Virtual Projects}

In order to investigate the use of the virtual simulation platform, a questionnaire for the students was carried out online. The questionnaire was released in the major of construction, environment and civil engineering of our university, and 115 students participated in the survey. Among them, 84 students have used the national virtual project experimental platform, and the participation rate is $73 \%$. The reasons for using the platform are shown in Figure 2. The graduation practice requirements account for $81 \%$, and the graduation design requirements account for $29.8 \%$. The students' evaluation of the virtual simulation platform is shown in Figure 3, in which the experimental steps are clear and easy to operate account for $69 \%$, and $64.3 \%$ of them were available for learning anytime.

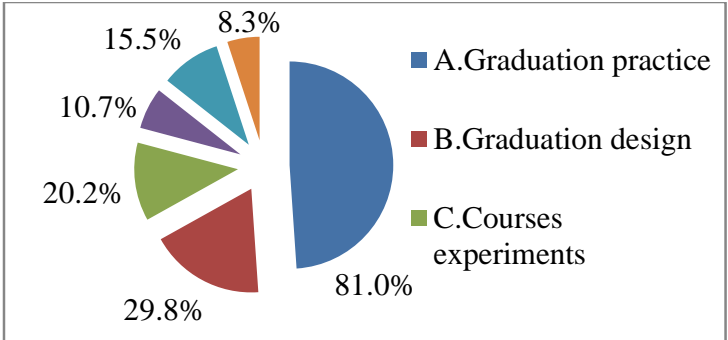

Figure 2 Proportion distribution of different requirements to visit virtual simulation platforms

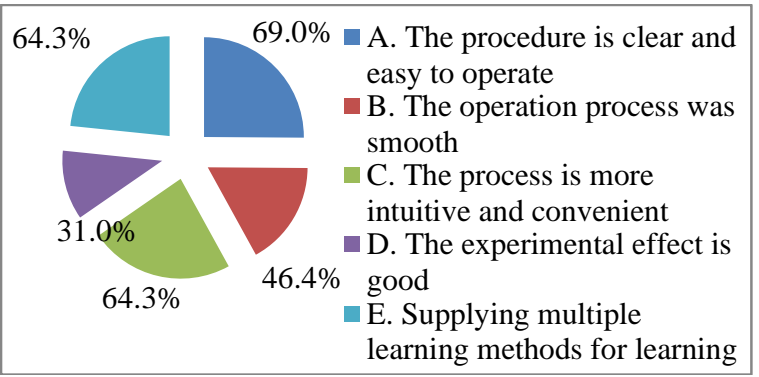

Figure 3 Proportion distribution of students' evaluation of virtual simulation platforms

\subsection{Advantages and Disadvantages for Students with Using the Simulation Platforms of Virtual Projects}

\subsubsection{Advantages of the Virtual Projects}

After using the virtual simulation experiment projects, $67.9 \%$ of students basically mastered the process and operation precautions of the virtual projects, $3.6 \%$ of them were unclear, $35.7 \%$ of them were clear about the structure and working principle of the experiment devices in the virtual systems, $59.5 \%$ of them were partially clear, $4.8 \%$ of them were unclear.64.3\% of them can promote the understanding of professional knowledge through operating of the virtual simulation experiment project. The proportion of those who master $50 \%-80 \%$ of the professional knowledge involved is $44 \%$.

\subsubsection{Disadvantages of the Virtual Projects}

As shown in Figure 4, 64.3\% of students think that it is not easy for the virtual simulation experiment platform to set its own experimental parameters and measurement methods, and $54.8 \%$ of the students think that the process is not clear and easy to operate.

Although the virtual simulation experiment platform has some shortcomings, the students' scores on the platform are more than 3 points, mainly 4 points, as shown in Figure 5. They think that the virtual simulation experiment project platform should be vigorously promoted and be a good helper for learning.

More than $90 \%$ of the students think that the virtual simulation platforms can not replace the traditional 
laboratory practice, more than $80 \%$ of the students agree that the virtual simulation experiment project platform is helpful for professional learning, but it cannot completely replace the on-site experimental operation, and some students think that the flexibility of the simulation experiment project is small.

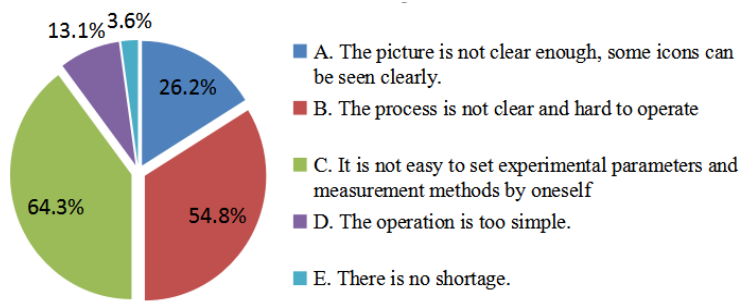

Figure 4 Proportion distribution of insufficient virtual simulation platforms

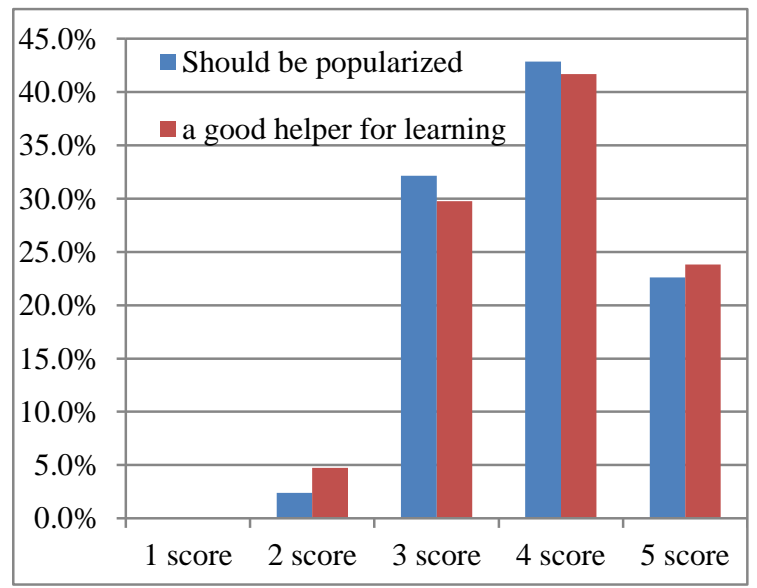

Figure 5 Proportion distribution of students' scoring on virtual simulation platforms

\section{IMPROVEMENTS TO THE VIRTUAL PLATFORMS}

\subsection{Build a Virtual Simulation Project Combined with the Actual Typical Project}

According to the requirements of practical teaching, selecting the typical construction projects which can be visited on sites, use virtual technology to build the real scenes of buildings, improve the construction of supporting systems in the building, such as water heating, electricity system, and carry out virtual operation, maintenance, management and debugging of these systems. The equipment in the building can be explained, and the system virtual system can be seen or experienced through the VR glasses and data software.

\subsection{Supply the Flexibility and Feasibility to Set Parameters Independently in the Virtual Project}

By increasing the self-set experiment parameters in the virtual procedures, the virtual adjustment and operation functions of equipment are provided. It can operate with a series of operating modes, such as operating the virtual adjustable valves, equipment start-stop buttons and so on, then the students can learn more about the actual systems. And also increases the sense of onsite operation[7].

\subsection{Supply the Mixed Practice Teaching Modes with Online and Offline}

Through online virtual simulation preview, combined with the offline field operation and observation, it can achieve better effect for students to understand the actual engineering, and also improve the engineering ability.

\section{CONCLUSION}

With the application of MOOC, the conventional classroom teaching will be greatly impacted. It is an urgent task to introduce virtual reality technology into professional teaching, promote the further integration of information technology and education teaching, explore more advanced practical teaching ideas and ways, which will benefit more students. The advantages of high efficiency, high degree of freedom and low cost will be reflected when the mature virtual technology is used in the production practice, graduation practice and professional experiment of civil engineering specialty. Personal experiences are more convincing than empty and abstract preaching. New technology will bring new educational thinking and solve the problems that it cannot be solved at the project sites.

\section{ACKNOWLEDGMENT}

This work is supported by Department of Education of Hubei Province in China (No. 2018262). Besides, a very special acknowledgement is made to the editors and referees who made important comments to improve this paper.

\section{REFERENCES}

[1] https://baike.so.com/doc/5412367-5650493.html, Virtual reality technology.

[2] Ding N., Wang Y.: Application of virtual reality in Education: advantages and challenges, Modern Educational Technology, Vol.27(2), pp.1925,2017. DOI:CNKI:SUN:XJJS.0.2017-02-004.

[3] Li X., Xu .n, Pan C.: Research on the application of virtual reality technology in college practice teaching, Education and Teaching Forum, Vol. 6,pp. 140-141,2018.DOI:CNKI:SUN:JYJU.0.201806-061

[4] Pan Y., Fu X., Chen M.: Reflection on cultivation of engineering thinking in undergraduate education 
of building environment and energy application engineering, HVAC, Vol.48(4), pp.1-6, 2018. DOI:CNKI: SUN: NTKT.0.2018-04-001

[5] Li Y., Du X., et al:. Exploration and practice of building virtual simulation experiment teaching center for civil engineering specialty, J.Teaching of China University, Vol..9, pp. 82-85,2014. DOI: CNKI: SUN: JXCY.0.2014-09-025

[6] Wang W.: Thoughts and suggestions on the construction of virtual simulation experiment teaching center, J.laboratory Research and Exploration, Vol. 32 (12), pp.5-8, 2013. DOI:CNKI:SUN:SYSY.0.2013-12-003

[7] Zhou Jason Xin; Shen Geoffrey Qiping; Yoon Sun Ho; Jin Xin, Customization of on-site assembly services by integrating the internet of things and BIM technologies in modular integrated construction, Automation in Construction Volume 126, 2021., DOI:10.1016/J.AUTCON.2021.103663 